\title{
More attention to attention? An eye-tracking investigation of selection of perceptual attributes during a task switch
}

\author{
Cai S. Longman, Aureliu Lavric*, and Stephen Monsell \\ Centre for Cognitive Control and Associative Learning, \\ Psychology, University of Exeter, Exeter, UK
}

(submitted as a Brief Report)

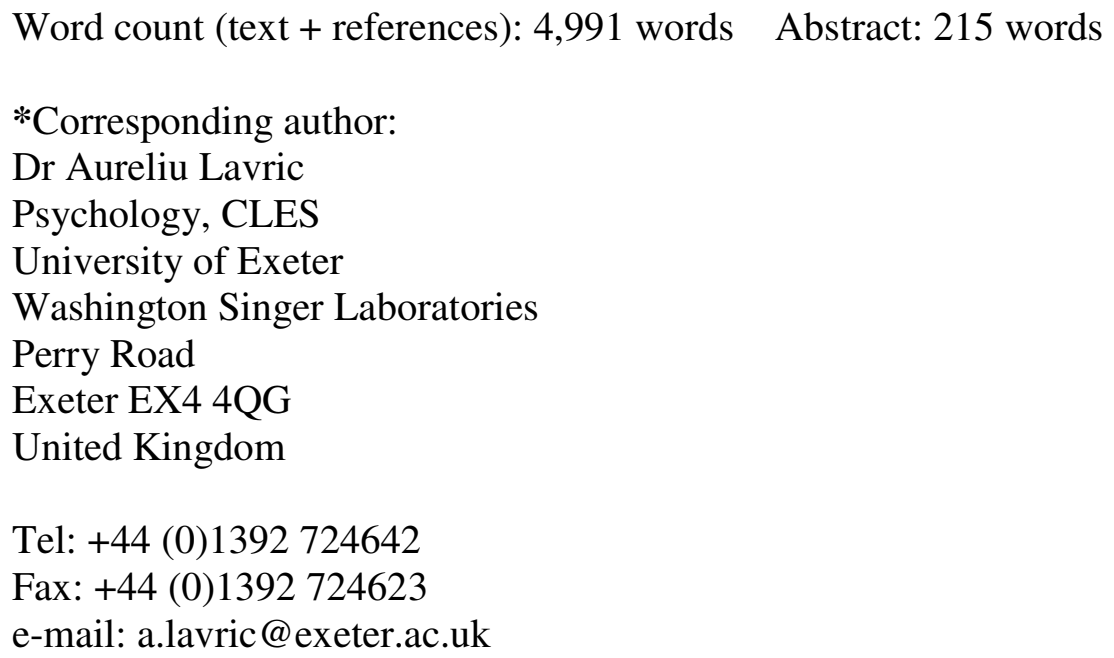

\section{Author Note}

The work described in this paper was carried out as part of an MSc project by CSL under the supervision of AL and SM. 


\begin{abstract}
Switching tasks prolongs response times, an effect reduced but not eliminated by active preparation. To explore the role of attentional selection of the relevant stimulus attribute in these task switch costs, we measured eye-fixations in participants cued to identify either a face or a letter displayed on its forehead. With only $200 \mathrm{~ms}$ between cue and stimulus onsets, the eyes fixated the currently relevant region of the stimulus less and the irrelevant region more on switch than on repeat trials, at stimulus onset and for $500 \mathrm{~ms}$ thereafter, in a pattern suggestive of delayed orientation of attention to the relevant region on switch trials. With $800 \mathrm{~ms}$ to prepare, both switch costs and inappropriate fixations were reduced, but on switch trials participants still tended (relative to repeat trials) to fixate the now-irrelevant region more at stimulus onset, and to maintain fixation on, or refixate, the irrelevant region more during the next $500 \mathrm{~ms}$. The size of this attentional persistence was associated with differences in performance costs between and within participants. We suggest that reorientation of attention is an important, albeit somewhat neglected and controversial, component of advance task-set reconfiguration, and that the task-set inertia (or reactivation) to which many attribute the "residual" task-switch cost seen after preparation includes inertia in (or reactivation of) attentional parameters.
\end{abstract}

Keywords: Task-switching, task-set, task-set inertia, selective attention, eye-tracking, control of attention. 
Performance of any cognitive task requires an appropriate organization and tuning of cognitive resources - a "task-set". Control of task-set has been extensively studied using task-switching paradigms (see Monsell, 2003; Kiesel et al., 2010; Vandierendonck, Liefooghe, \& Verbruggen, 2010). Typically the participant is introduced to two or three tasks afforded by a set of stimuli. Then on each of a series of trials a stimulus is presented and one task must be performed. The task may be specified in several ways. In the taskcuing paradigm (Meiran, 1996) used in the present study, each stimulus is preceded by a task-cue; the interval between cue and stimulus can be varied to control the time available for task preparation. Responses are usually slower and often more error-prone on taskswitch trials. Increasing the cue-stimulus interval (CSI) substantially reduces this "switch cost"; a CSI of about two thirds of a second usually suffices to reduce the RT cost to an asymptotic minimum - the "residual" switch cost. The reduction of switch cost with preparation is consistent with active reconfiguration of task-set (Rogers \& Monsell, 1995; Meiran 1996; Monsell \& Mizon, 2006) during the CSI, whilst the residual cost suggests some irreducible passive carry-over of task-set (Allport, Styles, \& Hsieh, 1994) or reactivation of the previous task-set (Wasczak, Hommel, \& Allport, 2003).

Even for the simple tasks typically used, there are multiple components of task-set that might need reconfiguration when the task changes, including attention to the appropriate stimulus attribute, and activation of appropriate $S-R$ rules. The typical emphasis has been on the latter, especially in accounts of the residual cost. Researchers have been particularly preoccupied with the extra difficulty of exercising currentlyrelevant S-R rules in the face of conflict from the previous S-R rules (e.g. Allport, Styles \& Hsieh, 1994; Crone, Wendelken, Donohue \& Bunge, 2006; Mayr \& Kliegl, 2000; 
Philip, Jolicoeur, Falkenstein \& Koch, 2007; Schuch \& Koch, 2003, Waszak et al, 2003; Wylie \& Allport, 2000; Yeung \& Monsell, 2003). Still, some influential computational accounts of task-set control have given a central role to the need to re-orient attention to the now-relevant perceptual attributes when the task changes. Logan and Gordon's (2001) ECTVA model contains a 'priority' parameter for computing the attentional weight given to each perceptual attribute of the stimulus. The switch cost is modeled as the time taken to transfer the value of this parameter and three other parameters (including a response category weight) from working memory into a task execution module. Meiran and colleagues' (Meiran, 2000a, b; Meiran \& Marciano, 2002; Meiran, Kessler \& Adi-Japha, 2008) modeling framework also distinguishes between weighting of perceptual attributes and weighting of response mappings and explicitly stipulates attentional re-weighting of perceptual input during a task-switch. An early account that emerged from this framework (Meiran, 2000a, b; Meiran \& Marciano, 2002) proposed that attentional weights can be adjusted prior to the imperative stimulus - hence the reduction in switch cost with opportunity for preparation - whereas response selection weights cannot - hence the residual switch cost. However, simulations using a more recent instantiation of this kind of model (CARIS, Meiran, Kessler \& Adi-Japha , 2008) led Meiran and colleagues to the different conclusion that attentional re-weighting requires the nearly simultaneous presence of the cue and the stimulus, and hence does not occur when the cue is presented in advance of the stimulus. Conversely, they proposed response selection weights are adjusted only when there is sufficient time for the cue to initiate the adjustment in advance of the stimulus. 
Evidence on the relative contribution of attentional and response-mapping adjustments remains scarce. Rushworth, Passingham and Nobre (2005) asked participants to attend to the color or shape of two geometric shapes each with a symbol superimposed, and respond to the identity of the symbol on the specified shape or color - e.g. the one on the red rather than the green shape, or on the rectangle rather than the triangle; a CSI of 1400 ms allowed ample time for preparation. Recordings of brain potentials (ERPs) revealed robust switch-repeat differences during the cue-stimulus interval (CSI). Because the $\mathrm{S}-\mathrm{R}$ rules remained constant, Rushworth et al. interpreted these ERP effects as indexing advance attentional resetting. The presence of switch cost despite ample opportunity for preparation further suggested inertia of attentional settings (though without a short CSI condition there was no direct evidence of how much preparation reduced the switch cost).

More recently, Lien, Ruthruff and Johnston (2010) asked participants to attend to different values on one perceptual dimension (color), rather than to different dimensions (e.g. color versus shape). The critical manipulation was the presentation in the late part of the CSI (shortly before the stimulus) of an uninformative 'cue' whose color and location did or did not match the to-be-attended color target. This uninformative cue captured attention (as indexed by faster responses to targets in its location) only when it occurred in the relevant color. Crucially, despite substantial switch costs, Lien et al. found no evidence of capture by the previously (but no longer) relevant color on switch trials either when the design required switching attention and the response set remained the same (Experiments 2 and 3), or when both attentional set and S-R switched (Experiment 4). In direct contrast with Meiran et al.'s (2008) proposal , Lien et al. (2010) concluded that, 
even in the 'tough' conditions that require switching of attentional and response sets, attention (at least to features) is switched during preparation, and that attentional processes are therefore unlikely to contribute significantly to the residual switch cost.

Thus, advance attention resetting and attentional inertia in task switching and their relationship to the switch cost, are, where not neglected, controversial. The present taskcuing study investigated post-stimulus attention to task-relevant and -irrelevant attributes of a compound stimulus using eye-tracking ${ }^{1}$. To do this, relevant and irrelevant attributes must be spatially separable. Many studies have used such stimuli (e.g. Rogers \& Monsell, 1995; Waszak et al, 2003; Yeung, Nystrom, Aronson, \& Cohen, 2006), and there is little reason to think that the switch-related phenomena observed are radically different from those observed in experiments employing spatially coextensive perceptual attributes or semantic attributes (e.g. Logan \& Bundesen, 2003; Monsell \& Mizon, 2006). If the attentional component of task-set is inappropriately tuned on task-switch trials, we should see more attention to the now-irrelevant attribute. Preparation might be expected to reduce any such difference. If some misallocation of attention persists even when there is opportunity for preparation and when preparation is effective (as indexed by performance), this would suggest 'attentional inertia'.

\footnotetext{
${ }^{1}$ Eye movements have been used as responses in studies of switching between pro- and anti-saccades (e.g. Hunt \& Klein, 2002), but we are not aware of studies using eye-tracking as an on-line index of attention in task-switching except for Mayr, Kuhns, \& Rieter (in press) and a conference paper by Masson (2009).
} 


\section{METHOD}

\section{Participants}

Twelve students ( 9 female) aged 21-37 (M=26) were paid $£ 12$ plus a performance-related bonus of up to $£ 2.40$.

\section{Stimuli}

A gray-scale photograph of one of four male faces (subtending $8.0^{\circ}$ horizontally and $10.9^{\circ}$ vertically; $70 \mathrm{~mm} \times 95 \mathrm{~mm} ; 160 \times 230$ pixels), with one of the four black uppercase letters $\mathrm{C}, \mathrm{G}, \mathrm{O}$, and $\mathrm{Q}\left(1.4^{\circ} ; 12 \mathrm{~mm}\right.$ x $12 \mathrm{~mm} ; 35$ x 35 pixels $)$ superimposed on its forehead (see Fig 1B), was presented centrally on a standard 19' CRT monitor at a resolution of $1024 \times 768$ pixels.

\section{Procedure and Design}

On each trial a central fixation cross was displayed until stimulus onset (see Fig. 1A). The onset of an auditory task cue lasting $400 \mathrm{~ms}$ preceded the onset of each stimulus by $200 \mathrm{~ms}$ or $800 \mathrm{~ms}$; the latter should be ample for asymptotic preparation (cf. Monsell \& Mizon, 2006), including a saccade to the relevant region (Rayner et al, 1983). The cue (one of four spoken words: "face" or "person"; "letter" or "sign") changed on every trial to unconfound cue and task change. Task switches were quasi-random with the constraint of a 1:2 switch:repeat ratio to discourage pre-cue anticipation of a task switch (cf. Monsell \& Mizon, 2006). The stimulus was presented until one of four keys was pressed using the index or middle fingers of either hand to identify the letter or face (as cued); the mapping of letters to responses (C, G, O, Q to keys 'a', 's', 'k', 'l', respectively) was 
constant over participants, as was the mapping of faces to the same keys. Thus, all 16 stimuli (4 letters $* 4$ faces) afforded both tasks; a quarter of them required the same response in the two tasks (congruent stimuli), whereas the remaining (incongruent) stimuli required different responses. The response-stimulus interval was $1650 \mathrm{~ms}$, regardless of CSI (to control for any decay of task-set inertia, Meiran, 1996), except following an error, when "ERROR" was displayed for an extra $1000 \mathrm{~ms}$.

Participants practiced each task in a 32-trial single-task block (with stimuli containing only the relevant attribute) and in two 49-trial task-switching blocks. Quasirandom trial sequences were generated in units of 192 trials containing one switch trial and two repeat trials per combination of task (2), face (4), letter (4) and cue (2). Each sequence was then divided into 4 blocks each containing 48 trials plus an additional randomly selected initial (filler) trial. Eye-movements and RTs were collected in 16 such blocks (768 trials), with CSI alternating between (and displayed before) blocks in an order balanced over participants. After each block participants received feedback on mean RT, error rate and a composite performance score; bonus payments were awarded for improvement relative to prior performance with the same CSI.

\section{Eye-tracking}

An EyeLink II head-mounted camera system (SR Research, Ottawa, Canada), calibrated before each block, tracked the right eye's fixations from stimulus onset to key-press with a sampling rate of $500 \mathrm{~Hz}$. For analysis the stimulus was segmented into 10 x 10 pixel squares ("hectopixels"). The fixation location at stimulus onset, and fixations over the following $800 \mathrm{~ms}$ were analysed to yield, for each hectopixel, a dwell time (duration of 
all fixations) and a number of fixations, for 32 successive $25 \mathrm{~ms}$ time-bins after onset ${ }^{2}$. Mean dwell-time and number of fixations were calculated for each subject, condition, hectopixel and time-bin.

Based on the importance of the eye-nose-mouth configuration for face identification, and on examination of fixation distributions, we defined two square regions as containing attributes important for the face task (19 x 19 hectopixels) and letter task (7 x 7 hectopixels) (see Fig. 1B), referred to henceforth as task- relevant or irrelevant. On repeat trials $89.3 \%$ of fixations fell within these two areas, $88.8 \%$ on switch trials. Blocks with $>20 \%$ of trials containing fixations elsewhere (suggesting poor calibration) were discarded: one block for four participants and five for a fifth $(4.7 \%$ overall). Trials following errors were excluded from all analyses, and error trials from eye-tracking and RT analyses. Huyhn-Feldt-corrected significance values are reported for all ANOVAs with uncorrected degrees of freedom.

\section{RESULTS AND DISCUSSION}

\section{Mean correct RTs and error rates (Fig. 1C)}

Switch $\mathrm{x}$ CSI $\mathrm{x}$ response congruence $\mathrm{x}$ task $\mathrm{ANOVAs}^{3}$ indicated reliable switch costs, $\mathrm{F}_{\mathrm{RT}}(1,11)=37.05, \mathrm{p}<0.001 ; \mathrm{F}_{\mathrm{ER}}(1,11)=16.55, \mathrm{p}=0.002$. With little opportunity for preparation $(\mathrm{CSI}=200)$ the $\mathrm{RT}$ switch cost was substantial $(124 \mathrm{~ms} ; 2.7 \%$ for error rate). A longer preparation interval $(\mathrm{CSI}=800)$ reduced switch cost for RTs, but not errors (switch by CSI interaction, $\left.\mathrm{F}_{\mathrm{RT}}(1,11)=11.19, \mathrm{p}=0.007 ; \mathrm{F}_{\mathrm{ER}}(1,11)=1.13\right)$. Of the twelve

\footnotetext{
${ }^{2}$ We classified fixations in the 1-25 ms interval following the stimulus as reflecting the fixation at stimulus onset (along with fixations at $0 \mathrm{~ms}$ ) on the grounds that fixations initiated at very short latencies relative to the stimulus onset likely resulted from eye-movements programmed prior to stimulus onset.

${ }^{3}$ The F subscripts refer to ANOVAs on mean correct RT and error rate.
} 
participants, eleven showed a reduction in switch costs for RTs and eight for the error rate. However, there remained a residual switch cost of $67 \mathrm{~ms}, \mathrm{~F}_{\mathrm{RT}}(1,11)=11.19, \mathrm{p}=0.007$, and $1.5 \%, \mathrm{~F}_{\mathrm{ER}}(1,11)=11.19, \mathrm{p}=0.007$. The overall reduction in $\mathrm{RT}$ switch cost with preparation (46\%) was typical, and suggests that the experiment captured the usual difference between unprepared and prepared task-switching. Response incongruence prolonged RTs by $24 \mathrm{~ms}, \mathrm{~F}_{\mathrm{RT}}(1,11)=10.44, \mathrm{p}=0.008$, and increased error rates by $2.7 \%$, $\mathrm{F}_{\mathrm{ER}}(1,11)=16.73, \mathrm{p}=0.002$. This effect was greater on switch $(35 \mathrm{~ms}, 4.2 \%)$ than on repeat (13 ms, 1.3\%) trials, but the congruence by switch interaction was reliable only for errors, $\mathrm{F}_{\mathrm{ER}}(1,11)=13.23, \mathrm{p}=0.004$. Responses were overall faster in the face task $(805 \mathrm{~ms})$ than the letter task $(889 \mathrm{~ms}), \mathrm{F}_{\mathrm{RT}}(1,11)=15.2, \mathrm{p}=0.002$, but there was no statistically detectable asymmetry in the magnitude of switch cost between tasks.

\section{Eye movements}

Figures 2 and 3 show fixations and dwell-time on relevant and irrelevant regions, for the face and letter tasks, respectively. Given differences between tasks in the size and eccentricity of their target regions, and hence in the temporal dynamics of the associated eye movements, we assessed switch-related effects separately for the two tasks. We distinguish between "initial fixations" — gaze direction at stimulus onset, and "new fixations" - subsequent changes in fixation.

\section{Initial fixations}

Few new fixations were recorded in the first $150 \mathrm{~ms}$ (for either CSI), so fixation during this interval mostly reflects its locus before stimulus onset. That locus was predominantly 
within the face region, presumably because participants looked at the fixation cross before stimulus onset and because the face was larger than the letter. However, it is clear from Figures 2 and 3 (see fixations 'at onset') that switching reduced the bias towards the face region on face task trials and increases this bias on letter task trials. Thus, in addition to the overall bias towards the face region there was a switch-induced tendency to fixate the previously (but no longer) relevant region, as indicated by the significant switch by region interaction for both tasks: face, $\mathrm{F}(1,11)=19.48$, $\mathrm{p}=0.001$; letter, $\mathrm{F}(1,11)=21.28$, $\mathrm{p}=0.001$. This tendency reduced with $800 \mathrm{~ms}$ to prepare, but not reliably so, and the switch by region interaction was still reliable at $\mathrm{CSI}=800$ : face, $F(1,11)=11.55, \mathrm{p}=0.006$; letter, $\mathrm{F}(1,11)=15.04, \mathrm{p}=0.003$.

\section{Dwell-time and new fixations}

For the analysis of dwell-time and new fixations we defined time-windows to capture phases of fixation activity. The windows (whose boundaries are shown on the $\mathrm{x}$ axis in Figures 2 and 3) were not arbitrary, but corresponded to components identified by a temporal Principal Components Analysis of dwell times ${ }^{4}$; they differed between tasks to reflect differences in time course. We submitted dwell times and number of fixations to omnibus ANOVAs - time-window by switch/repeat by CSI by region [relevant/irrelevant] by congruence - and then examined particular time-windows of interest. We focus here on interactions involving switch/repeat, CSI, region, and time-

\footnotetext{
${ }^{4}$ We also ran ANOVAs on the principal components themselves (the component 'scores'), which are not presented here due to space limitations. They revealed the same pattern of effects of switching and preparation on dwell-time as in the more conventional analyses presented here.
} 
window $(\mathrm{TW})^{5}$. The omnibus ANOVA revealed for both measures and both tasks highly significant interactions involving factors switch, region, time-window and CSI (see Tables 1 and 2 for ANOVA results) ${ }^{6}$, suggestive of a time- and preparation-modulated effect of switch on eye movements.

For dwell-time, follow-up ANOVAs by time-window showed more orienting to the irrelevant (and less to the relevant) region on switch than on repeat trials, starting with the earliest time-window and extending into the second and third (see Tables 1 and 2). Preparation reduced this switch-induced bias towards the irrelevant region - the critical switch by region by CSI interaction was significant for the second and third timewindows. Despite this reduction, preparation did not eliminate the switch-induced bias towards the irrelevant region for these time-windows, as indicated by the reliable switch by region interaction in ANOVAs run for the long CSI condition alone: face task ${ }^{7}$, TW2, $\mathrm{F}_{\mathrm{D}}(1,11)=22.33, \mathrm{p}=0.001 ; \mathrm{TW} 3, \mathrm{~F}_{\mathrm{D}}(1,11)=12.55, \mathrm{p}=0.005$; letter task: TW2, $\mathrm{F}_{\mathrm{D}}(1,11)=22.31, \mathrm{p}=0.001 ; \mathrm{TW} 3, \mathrm{~F}_{\mathrm{D}}(1,11)=5.13, \mathrm{p}=0.045$.

A similar pattern emerged for the number of new fixations. On switch trials there was a greater tendency to fixate on the irrelevant region early in the latent interval - in TW2. This tendency reversed later - in TW4 - when there were more fixations to the relevant region on switch trials, suggesting a switch-induced delay in attending to the relevant region. Both early and late switch-repeat differences were strongly attenuated or

\footnotetext{
${ }^{5}$ As the time-windows were of unequal size, values were scaled to represent dwell-time as the $\%$ of the time-window and the number of fixations per $100 \mathrm{~ms}$.

${ }^{6} \mathrm{We}$ focus here on the effects involving the interaction of switch and region. Some region-independent effects of switch were also found, as were some effects involving congruence- these are presented in the Supplementary Materials at...[web address; currently on page 31].

${ }^{7}$ Subscripts $\left(F_{D}\right.$ and $\left.F_{N}\right)$ refer to ANOVAs on dwell time and number of fixations, respectively.
} 
eliminated at the long CSI (see the switch by region by CSI interactions in Tables 1 and 2).

As a more direct test of the switch-induced delay in attention, we subjected the mean latency of the first new fixation ( $>25 \mathrm{~ms}$ post-stimulus onset) on the task-relevant region to switch by CSI by task ANOVAs. The significant interaction between switch and CSI, $\mathrm{F}(1,11)=9.39, \mathrm{p}=0.011$, indicates a delay in the first new fixation to the relevant region on switch relative to repeat trials at the short CSI, eliminated at the long CSI (see Table 3).

\section{Ruling out an effect of oculomotor persistence}

Might the effect on initial fixation reported above be explained as mere "oculomotor persistence" — the gaze simply remaining directed towards the region attended to as relevant on the previous trial? Although we did not monitor fixation before the stimulus in this study, we can ask whether the tendency to fixate the task-irrelevant region on switch trials was present even for trials on which the initial fixation was central. We therefore selected trials on which the initial fixation was within 25 pixels of the centre of the fixation $\operatorname{cross}^{8}$ and examined the window starting at $150 \mathrm{~ms}$ and containing most of the early new fixations. Switch by region by CSI ANOVAs identified a robust tendency to fixate the irrelevant region more on switch trials for dwell-time in the face task, $\mathrm{F}_{\mathrm{D}}(1,11)=13.24, \mathrm{p}=0.004$, and for dwell-time and the number of fixations in the letter task, $\mathrm{F}_{\mathrm{D}}(1,11)=18.36, \mathrm{p}=0.001 ; \mathrm{F}_{\mathrm{N}}(1,11)=9.84, \mathrm{p}=0.009$. Although this tendency was reliably reduced by preparation in the dwell-time data (switch by region by CSI interaction: face task, $\mathrm{F}_{\mathrm{D}}(1,11)=8.11, \mathrm{p}=0.016$; letter task, $\left.\mathrm{F}_{\mathrm{D}}(1,11)=7.67, \mathrm{p}=0.018\right)$, it

\footnotetext{
${ }^{8}$ On average 192 face-task trials (50\%) and 142 letter-task trials (37\%).
} 
was still reliable in the long CSI for both the face task, $\mathrm{F}_{\mathrm{D}}(1,11)=14.28, \mathrm{p}=0.003$, and the letter task, $\mathrm{F}_{\mathrm{D}}(1,11)=4.83, \mathrm{p}=0.05$. These results strongly suggest attentional inertia, rather than mere gaze persistence.

\section{Relationship between eye-fixations and performance}

Does the attentional "handicap" apparently associated with switching tasks contribute directly to the performance cost? Analysis of RT distributions of long CSI trials typically shows smaller switch costs for fast than slow responses, consistent with considerable variability in the efficiency of task-set preparation (De Jong, 2000; Nieuwenhuis \& Monsell, 2002). Binning the RTs, separately for switch and repeat trials, into terciles (cf. Lavric, Mizon \& Monsell, 2008) showed the same pattern here: switch costs were $41 \mathrm{~ms}$ for the fastest third, significantly smaller than $104 \mathrm{~ms}$ for the slowest third, $\mathrm{F}(1,11)=5.98$, $\mathrm{p}=0.033$. In the eye-movement data (see Fig. 4), switch by region by RT tercile by timewindow ANOVAs found substantially greater switch-repeat differences in the slowest third of trials than in the fastest third, particularly in the early part of the latent interval; face task: switch by region by tercile, $\mathrm{F}_{\mathrm{D}}(1,11)=9.82, \mathrm{p}=0.01$; switch by region by tercile by time-window, $\mathrm{F}_{\mathrm{D}}(4,44)=2.48, \mathrm{p}=0.065 ; \mathrm{F}_{\mathrm{N}}(3,33)=4.06, \mathrm{p}=0.015$; letter task: switch by region by tercile, $\mathrm{F}_{\mathrm{D}}(1,11)=4.02, \mathrm{p}=0.07 ; \mathrm{F}_{\mathrm{N}}(1,11)=7.66, \mathrm{p}=0.018$; switch by region by tercile by time-window, $\mathrm{F}_{\mathrm{D}}(4,44)=3.6, \mathrm{p}=0.042 ; \mathrm{F}_{\mathrm{N}}(4,44)=6.17, \mathrm{p}<0.001$. Thus the greater tendency to mis-orient on switch trials is not epiphenomenal: it is associated with greater performance costs of switching, and poorer preparation for a switch.

We also correlated over participants the RT and error switch cost (each measure averaged over tasks and CSIs) with the switch-minus-repeat difference in the latency of 
the first post-stimulus fixation on the relevant region - a straightforward measure of switch-induced attentional delay . The correlation was significant for the errors, $\mathrm{r}(10)=0.58, \mathrm{p}=0.046$; for the $\mathrm{RT}$ it had the expected sign, but failed to reach significance $\mathrm{r}(10)=0.33$, ns.

\section{The 'residual' switch-repeat difference in fixations}

The above results show a tendency to fixate the irrelevant region more on switch trials even with $800 \mathrm{~ms}$ to prepare, which suggests that even when there is opportunity to change the attentional settings from the previous trial there is still detectable inertia of those settings - a potential contributor to the 'residual' switch cost. However, with only two CSIs, we cannot be confident that switch-related deficits in performance or gaze at the longer CSI reflect asymptotic preparation. Graded manipulations of CSI typically indicate asymptotic preparation achieved before $800 \mathrm{~ms}$ (e.g. Monsell \& Mizon, 2006), but the tasks and cues used here were different. However, if we limit analysis to the fastest RT tercile at the longer CSI (i.e. the best-prepared trials), switch by region ANOVAs on dwell-time in the time-window starting at $150 \mathrm{~ms}$ still yield a marginally reliable interaction in the appropriate direction for the letter task, $\mathrm{F}(1,11)=4.56, \mathrm{p}=0.056$; the equivalent interaction for the face task is in the same direction, though not reliably so, $\mathrm{F}(1,11)=1.42$.

\section{GENERAL DISCUSSION}

In a task-cuing experiment exhibiting typical effects on performance of task switches, preparation and response congruence, we examined eye-fixations during stimulus 
processing as an online index of spatial attention. On task-switch trials, attention was less well-oriented to the task-relevant region of the stimulus, both at stimulus onset and over the first 400-500 ms thereafter. That attention should be initially misoriented with little or no time for preparation in the CSI=200 ms condition is to be expected. More interesting are observations suggesting that switching tasks induces a substantial additional delay in orienting attention appropriately, namely: the overall shift in dwell times and number of fixations from an early switch-related bias towards the irrelevant region to a later bias to the relevant region, and a longer average latency of the first fixation on the relevant region. These observations suggest that resetting of attentional parameters, as part of task-set reconfiguration, takes time to accomplish over the early part of the latent interval, when there has been no opportunity beforehand. Comparisons of fast (wellprepared) to slow responses and correlations over individuals indicate a functional relation between this attentional misorienting and difficulty in switching tasks and preparing to switch as indexed by performance. This is inconsistent with Lien et al.'s (2010) suggestion that attentional delays are unlikely to contribute to task switch costs. It also shows that, contrary to some recent accounts (Altmann \& Gray; 2008; Schneider \& Logan, 2005), switch costs are not just a consequence of reduced priming of cueencoding or task-representations.

With $800 \mathrm{~ms}$ for preparation between task-cue and stimulus, the tendency to orient more towards the irrelevant region on switch trials was (like the performance cost of a switch) reduced. This does not agree with Meiran et al.'s (2008) recent proposal that the resetting of attentional parameters requires the presence of the stimulus, but it is consistent with Meiran and colleagues' (Meiran, 2000 a, b; Meiran \& Marciano, 2002) 
earlier account which assumed advance resetting of attentional weights to the values appropriate to the cued task.

Although the bias to fixate the now-irrelevant (but previously relevant) region on switch trials was strongly reduced by preparation, it was not eliminated. In the long CSI trials, this bias persisted until 400-500 ms following stimulus onset, was detectable for the third of trials with the fastest (most well-prepared) responses, and was observed even for fixations away from the fixation cross made after stimulus onset. These observations suggest that task-set inertia (or associative reactivation, Waszak et al., 2003) to which many theorists have attributed residual switch costs reflects inertia in (or reactivation of) attentional settings, not just the S-R mappings. These observations also run contrary to Lien et al.'s (2010) claim that, following preparation, the relevant attentional settings are immune to competition from the irrelevant settings.

Evidently, two CSIs are insufficient to demonstrate that preparation was asymptotic at the longer CSI, though previous research has found $800 \mathrm{~ms}$ to be sufficient (e.g. Monsell \& Mizon, 2006), and other evidence indicates that it is more than ample for cuing a voluntary saccade (Rayner, 1998). Eye-tracking experiments in our lab tracing out the preparation function over a longer CSI (with a different set of tasks) also suggest $800 \mathrm{~ms}$ is ample (Longman, Lavric \& Monsell, in preparation). These experiments also address two other limitations of the current paradigm: that it did not monitor eye movements during the CSI, and that it did not address the possibility that the delay and inertia observed could be characteristic of shifts of spatial attention in general, rather than task-related attention. It is conceivable (if unlikely given what is known about attentional dynamics) that equivalent inertia would be present when the location of the target 
stimulus changes from trial to trial in the same way without a change of task. The Longman et al. (in preparation) study uses stimuli and tasks designed to allow a control condition in which participants have to shift spatial attention in just the same way but without changing task: this generates much smaller delays at a short CSI and no detectable inertia at long CSIs.

Our use of eye-tracking here provides a measure only of spatial attention. We speculate, nevertheless, that persistence in, and time required to reconfigure, attentional bias may also be important when switching between spatially coextensive perceptual dimensions such as colour versus shape, or between non-perceptual attributes such as semantic properties of words or objects. Attention as biased competition between stimulus attributes (Desimone \& Duncan, 1995) is common theoretical currency, and dimensional weighting is a standard parameter in models of attentional control (e.g. Logan \& Gordon, 2001). However, as we noted earlier, most theorists have tended to focus on interference with response selection as the source of the cost of a task-switch, especially its residual component. Although our performance measures do provide evidence of conflict at the level of response selection (effects of response congruence and their interaction with switch) which may well contribute to the residual switch cost, our eye-movements results encourage greater attention to inertia in attentional set, both as a source of the residual switch cost and as part of what task-set reconfiguration must overcome. 


\section{REFERENCES}

Allport, D. A., Styles, E. A., \& Hsieh, S. (1994). Shifting intentional set: Exploring the dynamic control of tasks. In C. Umilta \& M. Moscovitch (Eds.), Attention and performance $X V$ : Conscious and nonconscious information processing, (pp. 421-452). Cambridge: MA: MIT Press.

Altmann, E., \& Gray, W.D. (2008) An integrated model of cognitive control in task switching. Psychological Review, 115, 602-639.

Crone, E. A., Wendelken, C., Donohue, S. E., \& Bunge, S. A. (2006). Neural evidence for dissociable components of task-switching. Cerebral Cortex, 16, 475-486.

De Jong, R. (2000). An intention-activation account of residual switch costs. In S. Monsell \& J. Driver (Eds), Control of Cognitive Processes XVIII: Attention and Performance, (pp. 357-376). Cambridge, MA: MIT Press.

Desimone, R., \& Duncan, J. (1995). Neural mechanisms of selective visual attention. Annual Review of Neuroscience, 18, 193-222.

Hunt, A. R., \& Klein, R. M. (2002). Eliminating the cost of task set reconfiguration. Memory \& Cognition, 30, 529-539.

Kiesel, A., Steinhauser, M., Wendt, M., Falkenstein, M., Jost, K., Philipp, A.M., \& Koch, I. (2010). Control and interference in task-switching: A review. Psychological Bulletin, 136, 849-874. 
Lavric, A., Mizon, G. A., \& Monsell, S. (2008). Neurophysiological signature of effective anticipatory task-set control: a task-switching investigation. European Journal of Neuroscience, 28, 1016-1029.

Lien, M-C., Ruthruff, E., \& Johnston, J. C. (2010). Attentional capture with rapidly changing attentional control settings. Journal of Experimental Psychology: Human Perception and Performance, 36, 1-16.

Logan, G. D., \& Bundesen, C. (2003). Clever homunculus: Is there an endogenous act of control in the explicit task-cueing procedure? Journal of Experimental Psychology: Human Perception and Performance, 29, 575-599.

Logan, G. D., \& Gordon, R. D. (2001). Executive control of visual attention in dual-task situations. Psychological Review, 108, 393-434.

Longman, C. S., Lavric, A., \& Monsell, S. (in preparation). Attentional inertia and delays in task-appropriate orienting accompany a task switch: evidence from eye tracking.

Masson M.E.J. (2009, November) Lag-2 repetition cost in task switching: backward inhibition or gambler's fallacy? Paper presented at the $50^{\text {th }}$ meeting of the Psychonomic Society, Boston.

Mayr, U., \& Kliegl, R. (2000). Task-set switching and long-term memory retrieval. Journal of Experimental Psychology: Learning, Memory, and Cognition, 26, 11241140.

Mayr, U., Kuhns D., \& Rieter, M. (in press). Eye movements reveal dynamics of task control. Journal of Experimental Psychology: General. 
Meiran, N. (1996). Reconfiguration of processing mode prior to task performance. Journal of Experimental Psychology: Learning, Memory and Cognition, 22, 14231442.

Meiran, N. (2000a). Modeling cognitive control in task-switching. Psychological Research, 63, 234-249.

Meiran N, (2000b) Reconfiguration of stimulus task sets and response task sets during task switching. In: S. Monsell S \& J. Driver (Eds) Attention and Performance XVIII: Control of Cognitive Processes (pp. 307-400). Cambridge MA: MIT Press.

Meiran, N., Kessler, Y., \& Adi-Japha, E. (2008). Control by action representation and input selection (CARIS): a theoretical framework for task switching. Psychological Research. 72, 473-500.

Meiran, N, \& Marciano, H. (2002). Limitations in advance task preparation: Switching the relevant stimulus dimension in speeded same-different comparisons. Memory and Cognition, 30, 540-550.

Monsell, S. (2003). Task switching. Trends in Cognitive Sciences, 7, 134-140.

Monsell, S., \& Mizon, G. A. (2006). Can the task-cueing paradigm measure an “endogenous" task-set reconfiguration process? Journal of Experimental Psychology: Human Perception and Performance, 32, 493-516.

Nieuwenhuis, S., \& Monsell, S. (2002). Residual costs in task switching: testing the failure-to-engage hypothesis. Psychonomic Bulletin and Review, 9, 86-92.

Philipp, A. M., Jolicoeur, P., Falkenstein, M., \& Koch, I. (2007). Response selection and response execution in task switching: Evidence from a go-signal paradigm. Journal of Experimental Psychology: Learning, Memory, and Cognition, 33, 1062-1075. 
Rayner, K. (1998). Eye Movements in Reading and Information Processing: 20 Years of Research. Psychological Bulletin, 124, 372-422.

Rayner, K., Slowiaczek, M. L., Clifton, C., \& Bertera, J. H. (1983). Latency of sequential eye movements: implications for reading. Journal of Experimental Psychology: Human Perception and Performance, 9, 912-922.

Rogers, R. D., \& Monsell, S. (1995). Costs of predictable switch between simple cognitive tasks. Journal of Experimental Psychology: General, 124, 207-231.

Rushworth, M. F. S., Passingham, R. E., \& Nobre, A. C. (2005). Components of attentional set-switching. Experimental Psychology, 52, 83-98.

Schuch, S., \& Koch, I. (2003). The role of response selection for inhibition of task sets in task shifting. Journal of Experimental Psychology: Human Perception and Performance, 29, 92-105.

Schneider, D.W., \& Logan, G.D. (2005) Modeling task switching without switching tasks: A short-term priming account of explicitly cued performance. Journal of Experimental Psychology: General, 134, 343-367.

Vandierendonck, A., Liefooghe, B., \& Verbruggen, F. (2010). Task switching: interplay of reconfiguration and interference control. Psychological Bulletin, 136, 601-626.

Waszak, F., Hommel, B., \& Allport, A. (2003). Task-switching and long-term priming: role of episodic stimulus-task bindings in task-shift costs. Cognitive Psychology, 46, $361-413$.

Wylie, G. \& Allport, A. (2000) Task switching and the measurement of "switch costs". Psychological Research, 63, 212-233. 
Yeung, N. \& Monsell, S. (2003). The effects of recent practice on task switching. Journal of Experimental Psychology, Human Perception and Performance, 29, 919-936

Yeung, N., Nystrom, L. E., Aronson, J. A., \& Cohen, J. D. (2006). Between-task competition and cognitive control in task switching. Journal of Neuroscience, 26, $1429-1438$. 
FIGURES AND TABLES (along with the legends)

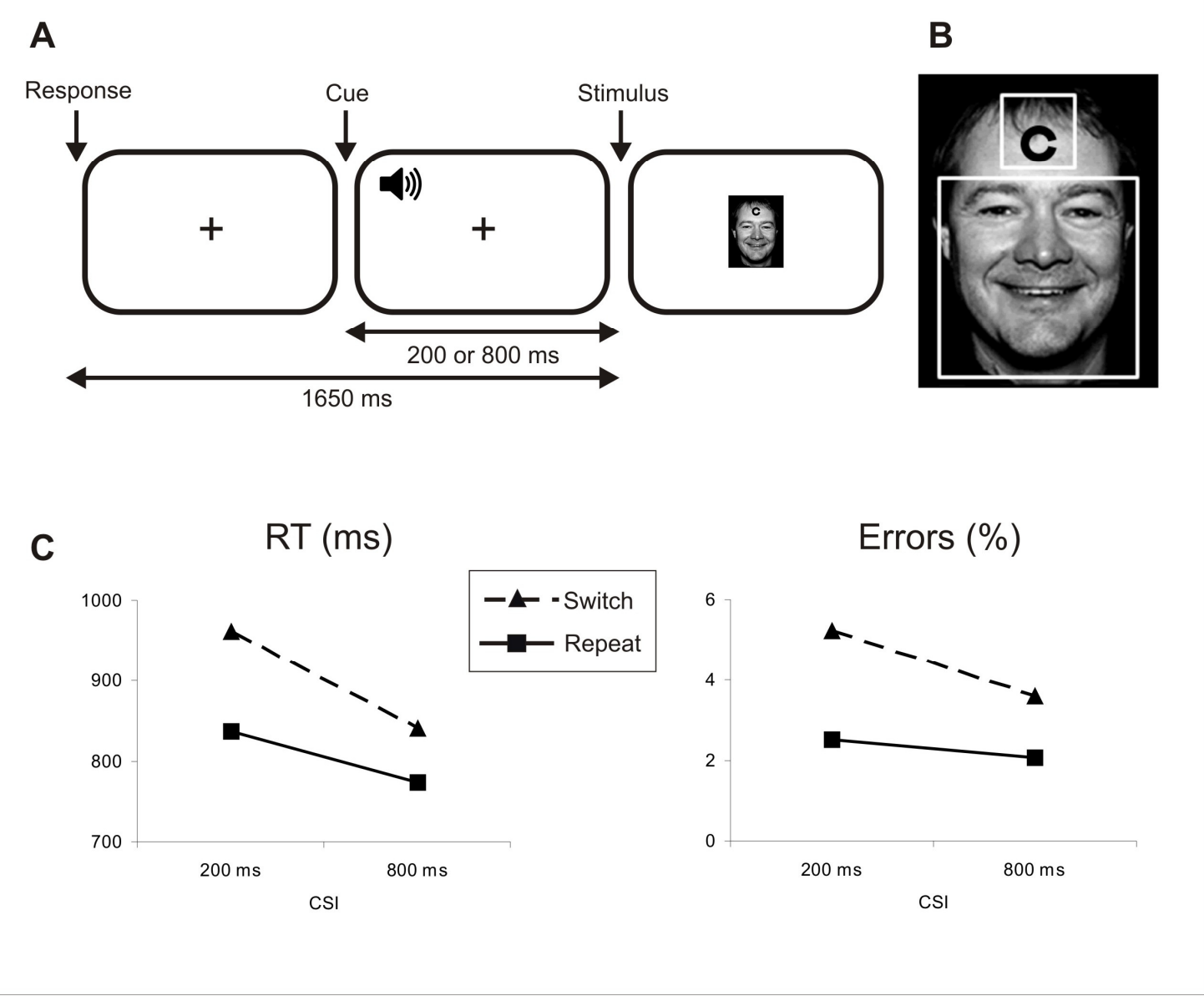

Figure 1. A. The time course of one trial. B. A stimulus with the regions used in the eyetracking analysis superimposed (in white). C. Response times and errors as a function of task switch/repeat and preparation interval. 


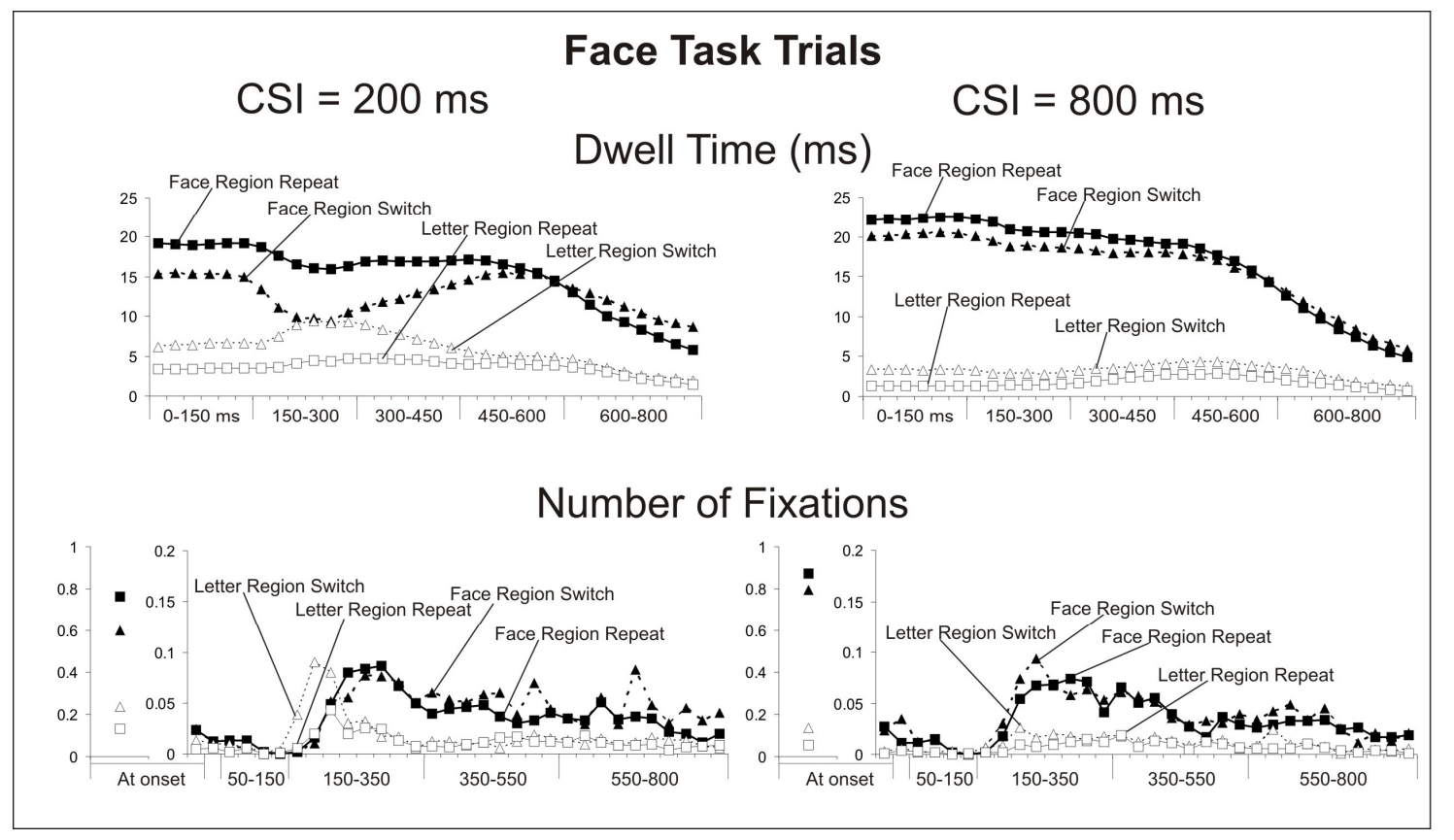

\begin{tabular}{|c|c|c|c|c|c|c|}
\hline & \multicolumn{6}{|c|}{ Dwell Time } \\
\hline & \multirow[b]{2}{*}{ Omnibus } & \multicolumn{5}{|c|}{ Time window (ms) } \\
\hline & & $\begin{array}{l}\text { TW } 1 \\
0-150\end{array}$ & $\begin{array}{c}\text { TW } 2 \\
150-300\end{array}$ & $\begin{array}{c}\text { TW } 3 \\
300-450\end{array}$ & $\begin{array}{c}\text { TW } 4 \\
450-600\end{array}$ & $\begin{array}{c}\text { TW } 5 \\
600-800\end{array}$ \\
\hline $\begin{array}{l}\text { SwitchRegion } \\
(\mathrm{df}=1,11)\end{array}$ & $21.18^{* *}$ & $18.84^{* *}$ & $34.66^{* * *}$ & $20.68^{* *}$ & & \\
\hline $\begin{array}{l}\text { Switch }{ }^{\star} \text { Region }{ }^{\star} \text { CSI } \\
(\mathrm{df}=1,11)\end{array}$ & & & 9.02 * & $5.01 *$ & & \\
\hline $\begin{array}{l}\text { Switch }{ }^{\star} \text { Region`Window } \\
(\mathrm{df}=4,44)\end{array}$ & $11.7^{\star \star \star}$ & & & & & \\
\hline $\begin{array}{l}\text { Switch }{ }^{\star} \text { Region }{ }^{\star} C S{ }^{\star} \text { Window } \\
\text { (df }=4,44)\end{array}$ & $5.05^{* *}$ & & & & & \\
\hline
\end{tabular}

\begin{tabular}{|c|c|c|c|c|c|}
\hline & \multicolumn{5}{|c|}{ Number of Fixations } \\
\hline & \multirow[b]{2}{*}{ Omnibus } & \multicolumn{4}{|c|}{ Time window (ms) } \\
\hline & & $\begin{array}{c}\text { TW } 1 \\
50-150\end{array}$ & $\begin{array}{c}\text { TW } 2 \\
150-350\end{array}$ & $\begin{array}{c}\text { TW } 3 \\
350-550\end{array}$ & $\begin{array}{c}\text { TW } 4 \\
550-800\end{array}$ \\
\hline $\begin{array}{l}\text { Switch*Region } \\
(\mathrm{df}=1,11)\end{array}$ & & & 4.9 * & & $5.55^{*}$ \\
\hline $\begin{array}{l}\text { Switch }{ }^{*} \text { Region }{ }^{\star} \text { CSI } \\
\text { (df }=1.11)\end{array}$ & & & $7.83^{*}$ & $4.97^{*}$ & \\
\hline $\begin{array}{l}\text { Switch }{ }^{\star} \text { Region }{ }^{*} \text { Window } \\
(\mathrm{df}=4,44)\end{array}$ & 5.23 * & & & & \\
\hline $\begin{array}{l}\text { Switch }{ }^{\star} \text { Region }{ }^{\star} C S{ }^{*} \text { Window } \\
\text { (df }=4,44)\end{array}$ & 7.24 ** & & & & \\
\hline
\end{tabular}

$* \mathrm{p}<0.05 ; * * \mathrm{p}<0.01 ; * * * \mathrm{p}<0.001$ 
Figure 2. Face task: eye-movement data. Dwell-time and number of fixations plotted as averages (per subject per trial) within 25-ms time-bins. Filled symbols are for the relevant (face) region and empty symbols for the irrelevant (letter) region; squares are for repeat trials and triangles for switch trials. Boundaries of the time-windows used for statistical analyses (see Table 1) are marked on the horizontal axis. Initial fixations (computed as the average number of fixations in the $0-25 \mathrm{~ms}$ following stimulus onset, see Footnote 2 in the text) are shown to the left of the number of fixation curve ('At onset'). The different scales of the y-axes for the initial fixation and 'new' (post-stimulus) fixations reflect the difference between the two measures. Unlike initial fixations, which could be initiated prior to stimulus onset, a new fixation could only count towards a given 25-ms bin if it started (if an eye-movement ended) within that bin. Although there was theoretical possibility of more than one fixation in a $25-\mathrm{ms}$ time-bin, the average number of fixations was never greater than 1 for the initial fixation and much lower subsequently due to relatively few fixations made per trial.

Table 1. Face task: Significant F-ratios from ANOVAs on dwell-time and the number of fixations (as shown in Figure 2) for the omnibus ANOVA that included time-window as a factor and for the follow-up ANOVAs for each time-window. 


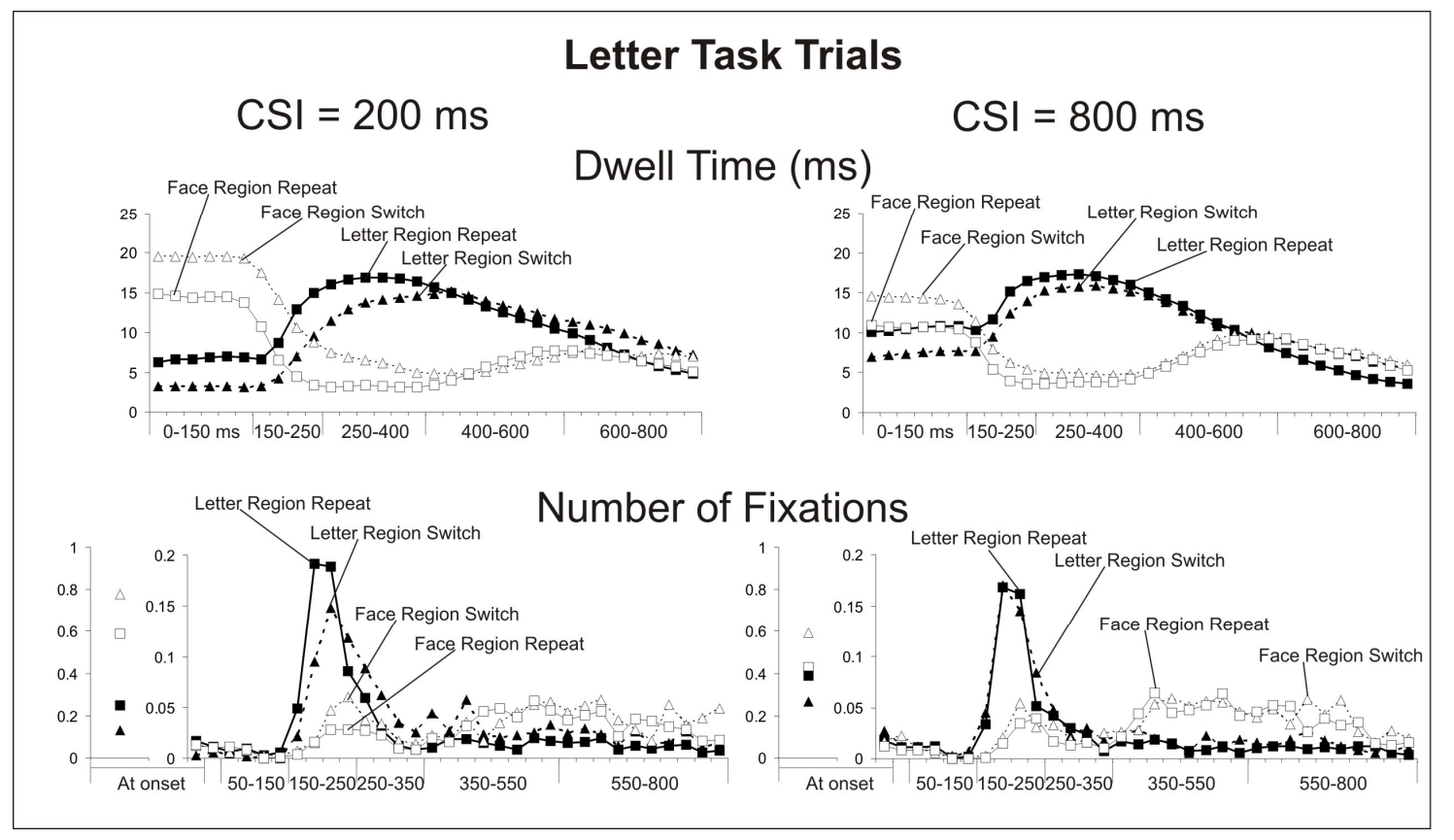

\begin{tabular}{|c|c|c|c|c|c|c|}
\hline & \multicolumn{6}{|c|}{ Dwell Time } \\
\hline & \multirow[b]{2}{*}{ Omnibus } & \multicolumn{5}{|c|}{ Time window (ms) } \\
\hline & & $\begin{array}{l}\text { TW } 1 \\
0-150\end{array}$ & $\begin{array}{c}\text { TW } 2 \\
150-250\end{array}$ & $\begin{array}{c}\text { TW } 3 \\
250-400\end{array}$ & $\begin{array}{c}\text { TW } 4 \\
400-600\end{array}$ & $\begin{array}{l}\text { TW } 5 \\
600-800\end{array}$ \\
\hline $\begin{array}{l}\text { Switch }{ }^{\star} \text { Region } \\
(\mathrm{df}=1,11)\end{array}$ & $35.26^{\star * *}$ & $22.42^{* *}$ & $55.96^{\star * *}$ & $23.35^{\star *}$ & & \\
\hline $\begin{array}{l}\text { Switch*Region }{ }^{\star} \text { CSI } \\
(\mathrm{df}=1,11)\end{array}$ & $17.44^{\star *}$ & & $19.67^{\star *}$ & $17.31^{* *}$ & & \\
\hline $\begin{array}{l}\text { Switch*Region*Window } \\
\text { (df }=4,44)\end{array}$ & $13.53^{\star * *}$ & & & & & \\
\hline $\begin{array}{l}\text { Switch }{ }^{\star} \text { Region }{ }^{\star} C S{ }^{\star} \text { Window } \\
(\mathrm{df}=4,44)\end{array}$ & $5.05^{* \star}$ & & & & & \\
\hline
\end{tabular}

\begin{tabular}{|c|c|c|c|c|c|c|}
\hline & \multicolumn{6}{|c|}{ Number of Fixations } \\
\hline & \multirow[b]{2}{*}{ Omnibus } & \multicolumn{5}{|c|}{ Time window (ms) } \\
\hline & & $\begin{array}{c}\text { TW 1 } \\
50-150\end{array}$ & $\begin{array}{c}\text { TW } 2 \\
150-250 \\
\end{array}$ & $\begin{array}{c}\text { TW } 3 \\
250-350 \\
\end{array}$ & $\begin{array}{c}\text { TW } 4 \\
350-550\end{array}$ & $\begin{array}{c}\text { TW } 5 \\
550-800\end{array}$ \\
\hline $\begin{array}{l}\text { Switch*Region } \\
(\mathrm{df}=1,11)\end{array}$ & & & $6.7^{*}$ & & $6.58^{*}$ & \\
\hline $\begin{array}{l}\text { Switch*Region*CSI } \\
(\mathrm{df}=1,11)\end{array}$ & & & $67.79^{* * *}$ & & & \\
\hline $\begin{array}{l}\text { Switch }{ }^{\star} \text { Region*Window } \\
(\mathrm{df}=4, \mathbf{4 4})\end{array}$ & $5.46^{*}$ & & & & & \\
\hline $\begin{array}{l}\text { Switch*Region }{ }^{*} C S{ }^{*} \text { Window } \\
\text { (df }=4,44)\end{array}$ & $10.17^{\star \star \star}$ & & & & & \\
\hline
\end{tabular}

$* \mathrm{p}<0.05 ; * * \mathrm{p}<0.01 ; * * * \mathrm{p}<0.001$ 
Figure 3. Letter task: Eye-movement data plotted as in Figure 2 except that the letter region is now the relevant region and the face region is the irrelevant region.

Table 2. Letter task. Significant F-ratios from ANOVAs on dwell-time and the number of fixations in the letter task, as plotted in Figure 3.

Table 3. Mean latency (in ms) of the first 'new' fixation on the relevant region.

\begin{tabular}{|l|c|c|c|c|}
\hline \multirow{2}{*}{} & \multicolumn{2}{|c|}{ Face task } & \multicolumn{2}{c|}{ Letter task } \\
\cline { 2 - 5 } & CSI=200 & CSI=800 & CSI=200 & CSI=800 \\
\hline switch & 394 & 363 & 319 & 285 \\
\hline repeat & 359 & 372 & 283 & 283 \\
\hline
\end{tabular}




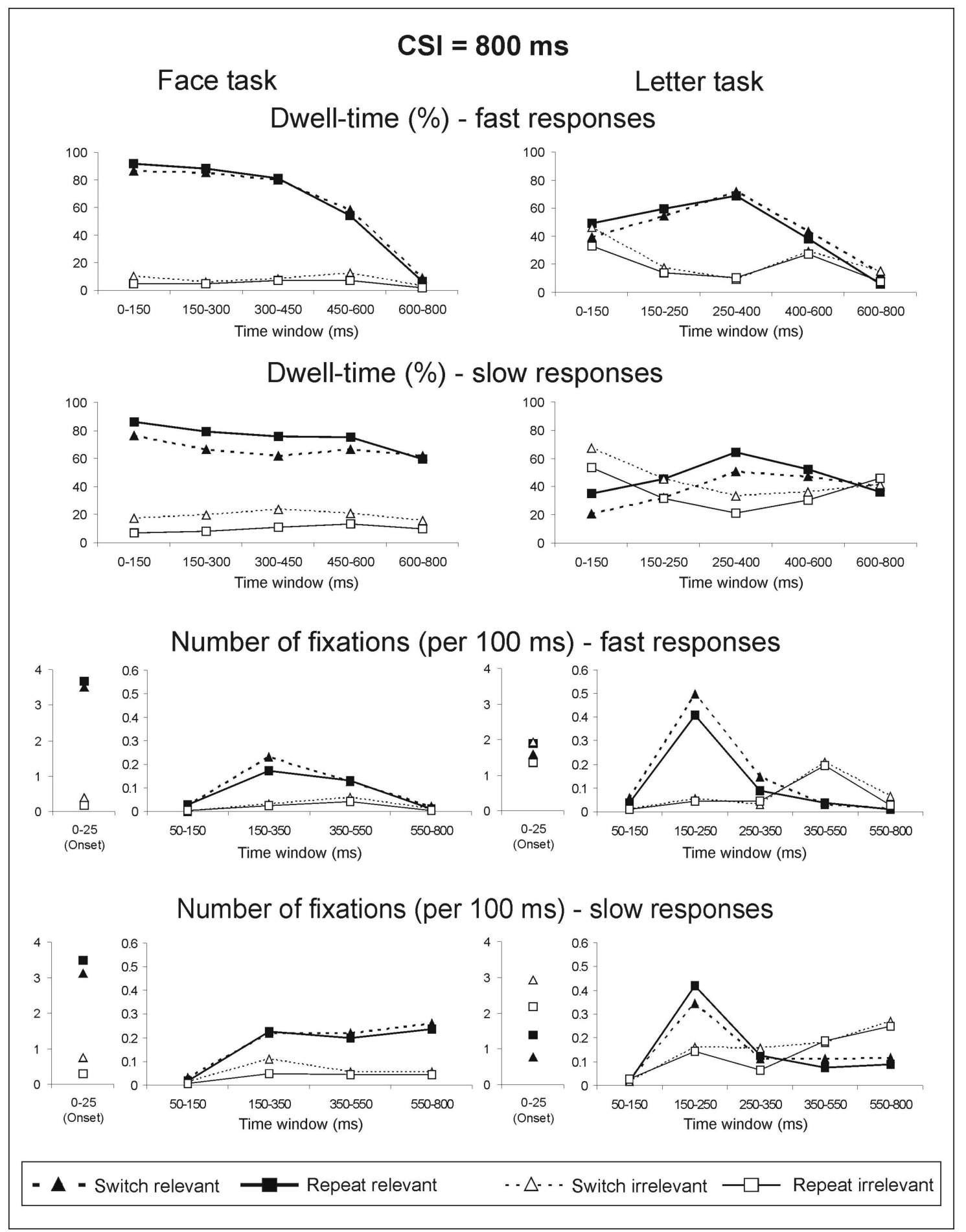

Figure 4. Dwell-time and number of fixations for the terciles of trials with the fastest and slowest RTs in the long CSI condition. The layout and the graphic conventions are the 
same as in Figures 2 and 3, except that averages for time-windows (rather than 25-ms bins) are presented; because the time-windows are not of equal size, the data have been scaled to represent dwell-time as the percentage of the time-window, and to show the average number of fixations per $100 \mathrm{~ms}$. 


\section{SUPPLEMENTARY MATERIALS}

\section{Switching effects independent of analysis region}

In addition to specific effects of switching on the balance of fixations between the relevant and irrelevant region, reported in the main text as interactions involving region (relevant, irrelevant), there were some overall effects of switching in these analyses, i.e. effects on the total dwell time, or number of new fixations, within the two defined regions. The omnibus ANOVAs found a significant main effect of switch on dwell-time for the letter task, $F_{D}(1,11)=20.06, p=0.001^{9}$, and on the number of fixations for both tasks $\left(\right.$ face, $\mathrm{F}_{\mathrm{N}}(1,11)=18.23, \mathrm{p}=0.001$; letter, $\left.\mathrm{F}_{\mathrm{N}}(1,11)=42.32, \mathrm{p}<0.001\right)$. There were $\sim 20 \%$ more fixations in time-windows 2 and 3 on face task trials and $\sim 37 \%$ more fixations in time-windows 3 and 4 on letter task trials, as well as $\sim 20 \%$ longer dwell-time in the last time-window on switch than on repeat trials (see Figures 2 and 3), reflected in the switch by time-window interaction $\left(\right.$ face, $\mathrm{F}_{\mathrm{D}}(4,44)=26.71, \mathrm{p}<0.001, \mathrm{~F}_{\mathrm{N}}(3,33)=3.73, \mathrm{p}=0.021$; letter, $\left.\mathrm{F}_{\mathrm{D}}(4,44)=8.66, \mathrm{p}<0.001, \mathrm{~F}_{\mathrm{N}}(4,44)=3.83, \mathrm{p}=0.03\right)$. Because the switch-induced tendency to fixate on the task-irrelevant region (see main text) was also the strongest in time-windows 2 and 3, the overall increase in the number of fixations (in both relevant and irrelevant regions) may reflect corrective fixations.

One can only speculate on the reasons for these differences. One would expect more corrective fixations in the short CSI (less time to prepare) and, for the letter task (smaller target), there was indeed a reliable switch by time-window by CSI interaction, $\mathrm{F}_{\mathrm{N}}(4,44)=7.19, \mathrm{p}=0.003$. More dwell-time within the defined analysis regions in the last time-window may reflect fewer fixations on the whole stimulus on repeat trials, for

\footnotetext{
${ }^{9}$ As in the main text, the subscripts refer to the dwell-time $\left(\mathrm{F}_{\mathrm{D}}\right)$ and number of fixation $\left(\mathrm{F}_{\mathrm{N}}\right)$ analyses.
} 
which, we presume, adequate perceptual information was sampled earlier than on switch trials. Again, one would expect this to be manifested more robustly at the short CSI and this was so, reliably for the face task (face, $F_{D}(4,44)=4.02, p=0.017$; letter, $F_{D}(4,44)=2.4$, $\mathrm{p}=0.12)$.

\section{Congruence effects in the eye-movement data}

The analyses of eye-movement data identified only modest effects of response congruence. The omnibus ANOVA on the number of fixations in the face task revealed a statistically significant interaction between congruence, region and time-window; $\mathrm{F}_{\mathrm{N}}(3,33)=3.21, \mathrm{p}=0.046$. Follow-up time-window analyses showed that congruence interacted significantly with region in the $150-350 \mathrm{~ms}$ window $\left(\mathrm{F}_{\mathrm{N}}(1,11)=4.9, \mathrm{p}=0.049\right)$, reflecting a somewhat larger relevant vs. irrelevant advantage on incongruent trials $(0.42$ mean fixations on the relevant region and 0.16 on the irrelevant region) than on congruent trials ( 0.40 vs. 0.19 , respectively). A similar tendency was suggested for dwell time for the letter task by the interaction between congruence, region, CSI and timewindow $\left(\mathrm{F}_{\mathrm{D}}(4,44)=3.71, \mathrm{p}=0.014\right)$ in the omnibus ANOVA, followed by the congruence by region by CSI interaction in the 400-600 ms time-window, $\mathrm{F}_{\mathrm{D}}(1,11)=5.43$, $\mathrm{p}=0.04$. The congruence by region interaction was marginally significant at the short CSI, $\mathrm{F}_{\mathrm{D}}(1,11)=4.04, \mathrm{p}=0.07$. These data might be taken to suggest that the detection of response conflict, on the incongruent trials, results in controlled focusing of attention. 